\title{
Radiation Characteristics of Corrugated Cardboard Flames
}

\author{
DONG ZENG, MARCOS CHAOS, MOHAMMED M. KHAN, and SERGEY B. DOROFEEV \\ FM Global, Research Division \\ 1151 Boston-Providence Turnpike \\ Norwood, MA 02062 USA
}

\begin{abstract}
The relation between flame radiation, smoke yield, and smoke point of a practical solid fuel, namely corrugated cardboard, is studied experimentally. Experiments are performed using an ASTM E 2058/ISO 12136 Fire Propagation Apparatus (FPA). Corrugated cardboard flames are established in the FPA under external heat fluxes representative of those found in a large-scale fire scenario. The heat release rates for these flames are on the order of 7 to $10 \mathrm{~kW}$ based on calorimetry analyses. Radiation is measured using a heat flux gage located in the near field of the flame. In order to better interpret calorimetry data, effort is placed on the characterization of the chemical composition and thermodynamics of the corrugated cardboard used both in its virgin and charred states. A novel smoke point measurement system based on the FPA is also described and demonstrated. It is shown that the specific heat of combustion of volatiles released from the pyrolysis process increases with pyrolysis progress. Furthermore, flame radiant fraction, smoke point, and smoke yield are also shown to vary during pyrolysis and combustion. The variations of both the smoke point and radiant fraction with pyrolysis progress at different heating rates indicate that the volatile chemical composition continuously varies during pyrolysis. These observations are explained by faster release rates of fuel oxygen and hydrogen than that of carbon during pyrolysis.
\end{abstract}

KEYWORDS: flame radiation, smoke yield, smoke point, solid fuel.

\section{INTRODUCTION}

Radiation heat transfer is the most important factor that affects growth rates and heat release rates of fires especially at large scales. Analytical and numerical models used to describe fire radiation and flame spread often rely on the correlation between the radiant emission from buoyant turbulent diffusion flames and parameters characterizing the sooting propensity of fuels, such as the laminar smoke point and smoke yield [1-6]. Several semi-empirical smoke point based radiation sub-models are available on the basis of these correlations [7, 8]. Chatterjee et al. [9] extended such a smoke point based global radiation model to a flamelet sub-model in the Large Eddy Simulation (LES) code FireFOAM [10]. These approaches are founded on an assumption that the fuel is homogeneous and can be assigned relatively constant global radiation properties.

Application of similar approaches to practical solid fuels is attractive because of their relative simplicity. Studies are available which use the correlations noted above to model flame heat transfer [11] and flame spread [12] in a medium-scale parallel panel geometry. However, while these correlations are well established for gaseous and liquid fuels, their application to practical solid fuels still requires additional foundation. Furthermore, although numerous experimental studies have been carried out on radiation emission from flames of gaseous or liquid fuels, only limited data are available on radiation from solid fuel flames $[13,14]$. For practical applications, it is important to develop an experimental technique that can be used to characterize smoke propensity of practical solid fuels and their relation with radiation emission. From these solid fuels corrugated cardboard represents the most widespread material for warehouse storage packaging. The objective of this study is to characterize the radiation emission from corrugated cardboard fires and its relations to experimentally measured laminar smoke points and smoke yields of the fuel.

As a charring material, corrugated cardboard undergoes combustion in two distinct stages: pyrolysis and subsequent heterogeneous char oxidation. The pyrolysis process produces volatiles that combust in a gas phase flame, while the heterogeneous char oxidation is flameless. Therefore, the combustion of volatiles is the major contributor to the flame and its radiation emission during a fire. Pyrolysis products are composed of complex hydrocarbons, the chemical composition of which depends on the virgin fuel composition as well as the pyrolysis process itself. Study of wood combustion revealed that the gross heats of combustion of volatiles change with increased fraction of weight loss [15]. Parker and LeVan [16] examined the heat of combustion of volatiles from several model compounds. The heat of combustion of volatiles released from 
alpha-cellulose increased from 10.6 to $15.5 \mathrm{~kJ} / \mathrm{g}$ with fractional mass losses ranging from 0.1 to 0.7 respectively, while those of mannan and xylan did not demonstrate a significant increase. These observations show that the pyrolysis behavior of charring fuels may affect the thermodynamic properties of pyrolysate gases, and consequently, flame radiation. Therefore, thermodynamic properties of volatiles released from corrugated cardboard are first studied.

The second part of this study investigates the global radiation characteristics of corrugated cardboard flames, including laminar smoke-point height, radiant fraction, and smoke yields (or smoke efficiency). Smoke-point height is defined as the length of a laminar diffusion flame at which the flame breaks open at its apex and emits a stream of smoke. While there is an ample amount of smoke-point height experimental data for gaseous and liquid fuels (e.g. [17]), similar data for solid fuels are rather limited [1, 18, 19]. Tewarson [1] measured smoke-point height of polymers using a Pyrex glass tube heated by a Bunsen burner. The smoke-point heights were measured visually by adjusting the gasification rate of the polymer. Delichatsios [18] investigated smoke-point height of PMMA and wood by pyrolyzing them at different heat fluxes. de Ris and Cheng [19] measured the smoke-point heights of both charring and non-charring solid fuels by translating material samples across the path of a laser beam, which created pyrolysis gases to support a "candle-like" flame. However, their results are nearly $40 \%$ lower than those obtained by Delichatsios [18]. For heterogeneous fuels, different pyrolysis conditions can alter the chemical composition of the pyrolysis gas, resulting in a variable smoke point. The different smoke-point heights measured by prior studies $[18,19]$ for similar materials can probably be attributed to the difference among experimental designs, especially the different heating conditions used. The same issue also poses a challenge when applying experimental smoke-point data to radiation models used in large-scale turbulent fire simulations; therefore the effect of pyrolysis on sooting processes needs to be better understood.

\section{EXPERIMENTAL APPROACH}

\section{Sample characteristics}

Double-wall corrugated cardboard was used in the present experiments. The material is characterized by the denomination 69-23B-69-23C-69 which represents the weight of the three linerboards $\left(327 \mathrm{~g} / \mathrm{m}^{2}\right.$, and $69 \mathrm{lb} / 1000 \mathrm{ft}^{2}$ in British unit) and the inner corrugated media $\left(112 \mathrm{~g} / \mathrm{m}^{2}\right.$, and $23 \mathrm{lb} / 1000 \mathrm{ft}^{2}$ in British unit). B-flute (154 flutes $/ \mathrm{m}, \sim 3 \mathrm{~mm}$ peak-to-peak) and C-flute (128 flutes $/ \mathrm{m}, \sim 4 \mathrm{~mm}$ peak-to-peak) corrugation is used. Relevant chemical analyses of the corrugated board in its virgin state were obtained from a commercial laboratory and are shown in Table 1.

Table 1. Fuel analyses of corrugated cardboard material.

\begin{tabular}{|c|c|c|c|c|c|c|c|c|c|}
\hline & \multicolumn{5}{|c|}{ Elemental Analysis (wt.\%, dry) } & \multicolumn{3}{c|}{$\begin{array}{c}\text { Proximate Analysis (wt.\%, as } \\
\text { received) }\end{array}$} \\
\hline $\begin{array}{c}\text { Net Heat of } \\
\begin{array}{c}\text { Combustion } \\
(\mathrm{kJ} / \mathrm{g} \text {, dry) }\end{array}\end{array}$ & $\mathrm{C}$ & $\mathrm{H}$ & $\mathrm{N}$ & $\mathrm{O} *$ & $\mathrm{~S}$ & $\begin{array}{c}\text { Fixed } \\
\text { Carbon }\end{array}$ & Volatile & Moisture & Ash \\
\hline 15.8 & 45.13 & 5.63 & $<0.5$ & 44.04 & 0.151 & 13.63 & 77.11 & 4.45 & 4.81 \\
\hline
\end{tabular}

* By difference.

\section{Experimental procedure}

Two types of experiments were performed in this study and are described below: combustions tests and smoke point measurement. For each type of experiment, the corrugated cardboard was prepared in different geometric configurations. For combustion tests, the material was cut into $5 \times 15 \mathrm{~mm}$ pieces to enhance the mass transfer rate of volatiles released during combustion. For all other tests, samples $95 \mathrm{~mm}$ in diameter were prepared in an insulated dish as described in [20]. For all tests, the corrugated cardboard samples were conditioned at $23^{\circ} \mathrm{C}$ and $50 \%$ relative humidity before testing (yielding $\sim 7 \%$ moisture content on a dry mass basis).

Figure 1a shows the FPA configuration used for the combustion tests. The solid fuel is loaded into a $140 \mathrm{~mm}$ I.D., $76 \mathrm{~mm}$ tall wire mesh sample holder placed on a load cell. A water-cooled shield is used to protect the sample from exposure while the heaters are stabilized at a specific heat flux setting. Air is fed, using mass flow controllers, through a bed of glass beads to ensure flow uniformity. In the present 
experiments the flow provided to the system was 200 (standard liters per minute), yielding an upward coflow of approximately $15 \mathrm{~cm} / \mathrm{s}$. A water-cooled Schmidt-Boelter heat flux gauge (MEDTHERM $0-100 \mathrm{~kW} / \mathrm{m}^{2}$ ) is used to measure flame radiation and is mounted at a position of $140 \mathrm{~mm}$ from the flame axis and $216 \mathrm{~mm}$ above the unburned sample surface. A CCD camera (ISG- LW-5-S-1394b-M) records flame images at a frame rate of $10 \mathrm{~Hz}$; this was done to reduce the exposure time so as to capture the instantaneous shape of the flame. An optional variable neutral density filter can be used to reduce light intensity and avoids over-exposure of the images. Combustion tests were carried out for the heat flux levels $30,50,70$, and $90 \mathrm{~kW} / \mathrm{m}^{2}$. For each heat flux level, a test is first conducted without fuel loaded in the system to obtain a baseline to be subtracted from heat flux measurements of burning samples. Flame products are collected by an exhaust duct where measurements are performed for the generation of $\mathrm{CO}_{2}$ and $\mathrm{CO}$ (using non-dispersive infrared analyzers), the consumption of $\mathrm{O}_{2}$ (using a paramagnetic analyzer), and the generation of smoke (by laser extinction) [21, 22]. Care was taken to remove extinction signals generated by pyrolysis volatiles released before a flame is established.

In order to measure smoke point of corrugated cardboard flames the FPA was retrofitted. Fig. 1b shows the process drawing of the smoke point measurement experimental system. An indirect combustion system was developed to decouple pyrolysis from combustion processes. Solid fuels are loaded into a quartz flask, mounted on a load cell, and externally heated by the FPA heaters. The pyrolysis volatiles flow through a vertical, $230 \mathrm{~mm}$ long, $9 \mathrm{~mm}$ I.D. thin-wall stainless tube and burn in a laminar flame with co-flow dry air regulated by a mass flow controller. The burner tube is centered in a $96 \times 96 \mathrm{~mm}$ square housing, in which the co-flow air velocity is maintained at $72 \mathrm{~mm} / \mathrm{sec}$. The temperature of pyrolysate is measured with a thermocouple inserted into the nozzle. An optional wire mesh can be installed around the flame length to further stabilize the flame.

Smoke point measurements were carried out for several heat flux levels ranging from 30 to $90 \mathrm{~kW} / \mathrm{m}^{2}$. The smoke point height was measured by visual observation and verified by the attenuation of a He- $\mathrm{Ne}$ laser beam [23]. For cases where the total volumetric flow rate of volatiles released by fuel pyrolysis is too large to establish a laminar flame, an eductor system is used which allows for excess volatile to be removed from the system, see Fig. $1 b$.

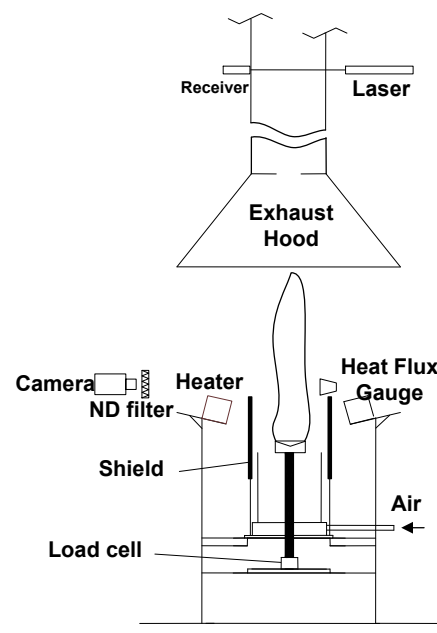

(a)

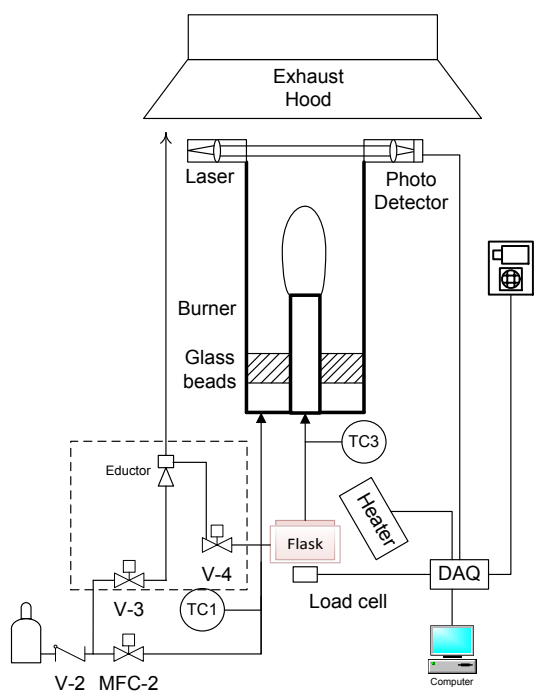

(b)

Fig. 1. (a) Combustion testing system; (b) Smoke point measurement system.

\section{Char preparation and thermodynamic analysis}

In order to interpret the radiation emission measurements obtained during combustion tests, effort was placed in determining the heat content and elemental composition of the corrugated material used, both in its virgin and charred states. To this end, the FPA was used to prepare char samples of corrugated cardboard. Samples were pyrolyzed in a quartz tube (162-mm ID) purged by nitrogen at four external heat 
flux levels: $30,50,70$, and $90 \mathrm{~kW} / \mathrm{m}^{2}$. In each pyrolysis test the sample was subjected to external heating until its mass loss rate dropped to zero. Samples were then allowed to cool down to room temperature in a nitrogen environment before being removed for analysis. Char samples were analyzed for elemental composition, heat of combustion, and ash content as listed in Table 2. Char yields are based on mass loss measured in the FPA tests.

Table 2. Analyses of char samples prepared from corrugated cardboard.

\begin{tabular}{|c|c|c|c|c|c|c|}
\hline \multirow{2}{*}{$\begin{array}{l}\text { External } \\
\text { Heat Flux } \\
\left(\mathrm{kW} / \mathrm{m}^{2}\right)\end{array}$} & \multicolumn{4}{|c|}{ Ultimate Analysis (wt.\%, dry) } & \multirow{2}{*}{$\begin{array}{l}\text { Char Yield } \\
\text { (wt.\%, dry) }\end{array}$} & \multirow{2}{*}{$\begin{array}{c}\text { Net Heat of } \\
\text { Combustion } \\
(\mathrm{kJ} / \mathrm{g} \text {, dry) }\end{array}$} \\
\hline & $\mathrm{C}$ & $\mathrm{H}$ & $\mathrm{O}^{*}$ & Ash & & \\
\hline 30 & 78.25 & 3.34 & 12.32 & 6.09 & 22 & 29.5 \\
\hline 50 & 82.34 & 2.53 & 7.91 & 7.22 & 18 & 30.5 \\
\hline 70 & 83.49 & 2.12 & 6.83 & 7.56 & 16 & 30.4 \\
\hline 90 & 84.23 & 1.66 & 6.16 & 7.95 & 12 & 30.5 \\
\hline
\end{tabular}

* By difference.

With the information provided by Tables 1 and 2, energy and elemental balances were performed to derive the thermodynamic characteristics of the volatiles. As shown in Table 1, the virgin material contains relatively small amount of elements such as nitrogen and sulfur that are neglected in the current analysis. The average elemental compositions of the volatiles are based on the following elemental balance between virgin material and char and on the assumption that they are only composed of carbon, hydrogen, and oxygen:

$\varepsilon_{i, \text { volatiles }}=\frac{1}{1-\mu}\left(\frac{\varepsilon_{i, \text { virgin }}}{1-\alpha_{\text {virgin }}}-\frac{\mu \varepsilon_{i, \text { char }}}{1-\alpha_{\text {char }}}\right)$

where $\varepsilon_{i}$ is the mass fraction of element $i(\mathrm{C}, \mathrm{H}$, or $\mathrm{O}), \mu$ is the char mass fraction, and $\alpha$ represents the mass fraction of ash. A general formula for the complete combustion of a given compound can be written as:

$\left(\mathrm{C}_{x} \mathrm{H}_{y} \mathrm{O}_{z} \mathrm{Ash}_{m}\right)_{j}+\left(x+\frac{y}{4}-\frac{z}{2}\right) \mathrm{O}_{2} \rightarrow x \mathrm{CO}_{2}+\frac{y}{2} \mathrm{H}_{2} \mathrm{O}+m \mathrm{Ash}$

Where $j$ is the compound of interest (virgin solid, char, or volatiles). Ash is included for completeness and for proper representation of the mass of the compounds; however, it is noted that it is considered inert, from a thermodynamic standpoint. The net heat of combustion, $\Delta H_{c, j}^{0}$, for the reaction expressed in Eq. 2, on a mass basis $(\mathrm{kJ} / \mathrm{g})$, is given by:

$\Delta H_{c, j}^{0}=\varepsilon_{\mathrm{C}, j}\left(\frac{1}{M_{\mathrm{C}}} \Delta h_{f, \mathrm{CO}_{2}}^{0}+\frac{\varepsilon_{\mathrm{H}_{j}}}{2 M_{\mathrm{H}} \varepsilon_{\mathrm{C}, j}} \Delta h_{f, \mathrm{H}_{2} \mathrm{O}}^{0}\right)-\Delta H_{f, j}^{0}$

Where $\Delta h_{f, \mathrm{CO}_{2}}^{0}$ is the molar heat of formation of carbon dioxide $(-393.51 \mathrm{~kJ} / \mathrm{mol}), \Delta h_{f, \mathrm{H}_{2} \mathrm{O}}^{0}$ is the molar heat of formation of water $(-44.004 \mathrm{~kJ} / \mathrm{mol}), M_{\mathrm{C}}$ and $M_{\mathrm{H}}$ are the molecular masses $(\mathrm{g} / \mathrm{mol})$ of elemental carbon and hydrogen, respectively, and $\Delta H_{f, j}^{0}$ is the mass-based heat of formation of compound $j(\mathrm{~kJ} / \mathrm{g}) ; 0$ superscripts denote standard conditions. The mass-based heats of formation of virgin material and char can be discerned from Eq. 3 and data for heat of combustion and elemental composition presented in Tables 1 and 2. One can now assume a single-step overall pyrolytic reaction that defines the heterogeneous conversion of virgin material to volatile gases and char. The pyrolysis heat evolved in this reaction is given, on a mass basis, as: 
$\Delta H_{p}^{0}=(1-\mu) \Delta H_{f, \text { volatiles }}^{0}+\mu \Delta H_{f, \text { char }}^{0}-\Delta H_{f, \text { virgin }}^{0}$

Where $\Delta H_{p}^{0}$ is the heat of pyrolysis $(\mathrm{kJ} / \mathrm{g})$. The heat of pyrolysis of cellulosic material varies with pyrolysis reaction temperature [24] and an average value of $0.126 \mathrm{~kJ} / \mathrm{g}$ has recently been measured by McKinnon [25] using differential scanning calorimetry for corrugated cardboard similar to the one used in this study; therefore, this value will be used herein. With known heat of pyrolysis along with the heats of formation of virgin material and char, the heat of combustion of volatiles generated for the heat flux conditions listed in Table 2 can be calculated combining Eqs. 3 and 4:

$$
\Delta H_{c, \text { volatiles }}^{0}=\varepsilon_{\mathrm{C}, \text { volatiles }}\left(\frac{1}{M_{\mathrm{C}}} \Delta h_{f, \mathrm{CO}_{2}}^{0}+\frac{\varepsilon_{\mathrm{H}, \text { volatiles }}}{2 M_{\mathrm{H}} \varepsilon_{\mathrm{C}, \text { volatiles }}} \Delta h_{f, \mathrm{H}_{2} \mathrm{O}}^{0}\right)-\frac{1}{1-\mu}\left(\Delta H_{p}^{0}+\Delta H_{f, \text { virgin }}^{0}-\mu \Delta H_{f, \text { char }}^{0}\right)
$$

\section{RESULTS AND DISCUSSIONS}

\section{Effect of heating rate}

Combustion testing of corrugated cardboard was carried out by subjecting the fuel to different external heat flux levels in order to vary the fuel pyrolysis rate. Fundamentally, the effect of external heat flux on the fuel is translated to a variation of fuel temperature and, specifically, the characteristic temperature range of thermal decomposition reactions that generate volatiles. The detailed mechanism of how fuel temperature and thermal decomposition reactions are affected by external heat flux is beyond the scope of this study. To illustrate such effect, however, surface and in-depth temperatures were measured. In addition, a simplified pyrolysis model was used to provide insights into the phenomena.

The temperature profiles measured at three locations in corrugated cardboard samples subjected to external heat fluxes of 30 and $90 \mathrm{~kW} / \mathrm{m}^{2}$ are shown in the left and right panels of Fig. 2, respectively. The tests were conducted in nitrogen atmospheres, as described previously, and consisted of samples prepared as described in for the smoke point tests wherein three layers of double-wall corrugated cardboard were stacked. In Fig. 2, curve 1 denotes the surface temperature (measured by an infrared pyrometer, Heitronics KT19.81-11); curves 2 and 3 correspond to the temperatures measured at the back surfaces of the first and second layers, respectively (using type K, $0.25 \mathrm{~mm}$ bead diameter, bare thermocouples). Different external heat fluxes affect both the temperature levels through the material as well as the fuel heating rate. For example, maximum surface temperatures of 545 and $823^{\circ} \mathrm{C}$ and surface heating rates of 19 and $47 \mathrm{~K} / \mathrm{s}$ were reached at 30 and $90 \mathrm{~kW} / \mathrm{m}^{2}$, respectively. For both heat flux levels, as shown by curves 2 and 3 , the temperature decreases with sample depth, due to transient heating effects. The equilibrium temperature and heating rates of in-depth locations are higher for the higher heat flux case. In general an increased external heat flux induces higher fuel temperatures and heating rates.
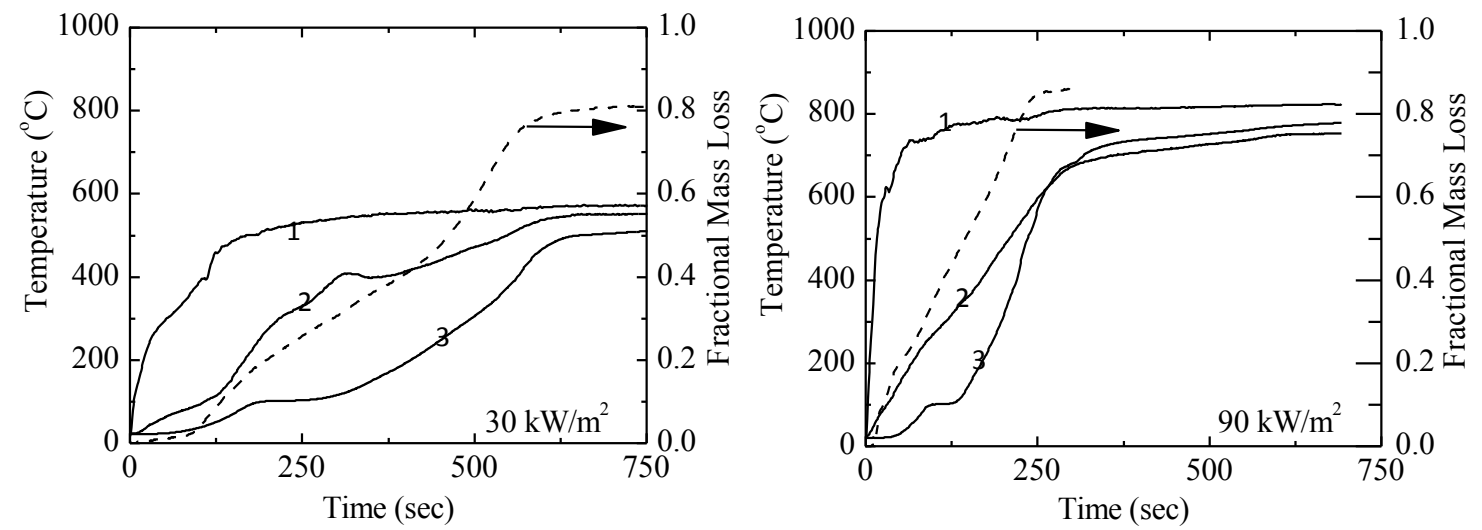

Fig. 2. Surface (curve 1) and in-depth (curves 2 and 3) temperatures during corrugated cardboard pyrolysis for heat fluxes of $30 \mathrm{~kW} / \mathrm{m}^{2}$ (left panel) and $90 \mathrm{~kW} / \mathrm{m}^{2}$ (right panel). 
Thermal decomposition reactions take place in-depth within the material as the thermal wave established due to external heating propagates. To illustrate the variation of the thermal pyrolysis regime and characteristic reaction temperatures with external radiant heat flux, a one-dimensional pyrolysis model [26] is used in the following numerical experiment. The fuel is assumed to be homogeneous and its physical properties are those determined for corrugated cardboard [26] through inverse modeling and optimization against an experimental dataset consisting of surface temperatures, mass loss rates, and cumulative mass losses collected over a wide range of heating conditions. In the model, the pyrolysis reaction is treated as a single brutto $n$ th-order Arrhenius-type decomposition reaction that converts virgin solid to char and gas. The materials properties and related model parameters are shown in Table 1 of reference [27]. In the numerical experiment, the initial fuel temperature is set to $300 \mathrm{~K}$ and external heat fluxes ranging between 25 and $100 \mathrm{~kW} / \mathrm{m}^{2}$ are considered. Figure $3 \mathrm{a}$ shows the temperature corresponding to the maximum pyrolysis reaction rate within the material as a function of pyrolysis progress (i.e. mass loss fraction) for representative heat fluxes. When the mass loss fraction is less than $\sim 0.7$, the temperature associated with the maximum reaction rate increases with heat flux level and is relatively constant with mass loss fraction. The dramatic change occur in the shape of the curves in Fig. 3a for mass loss fractions higher than 0.7, approximately. At this stage the material becomes thermally thin; and with modest back boundary heat losses, the heating rate and material temperature increases sharply with mass loss fraction.

Figure $3 \mathrm{~b}$ compares average temperatures (averaged between fractional mass loss levels of 0.2 and 0.6 ) corresponding to the maximum reaction rate as a function of imposed heat flux. An increasing trend can clearly be discerned. The data of Figs $3 \mathrm{a}$ and $3 \mathrm{~b}$ indicate that the characteristic pyrolysis reaction temperature increases both with external heat flux and with mass loss fraction exceeding the value approximately 0.7 . Although a single brutto reaction is used in this numerical experiment to illustrate the thermal regime, in reality there are numerous competing reactions that produce a range of volatiles, with their own temperature dependences. This should result in variations of the volatile composition with heat flux and reaction progress. Generally, heavier volatiles are expected to be produced with higher heat flux and at the end of the reaction progress.

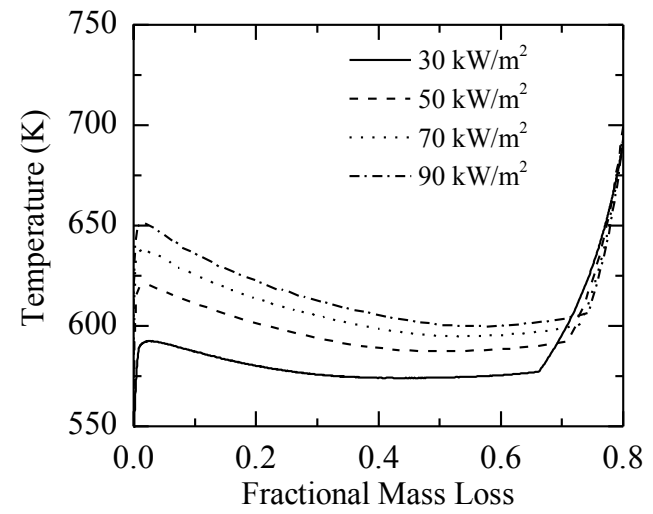

(a)

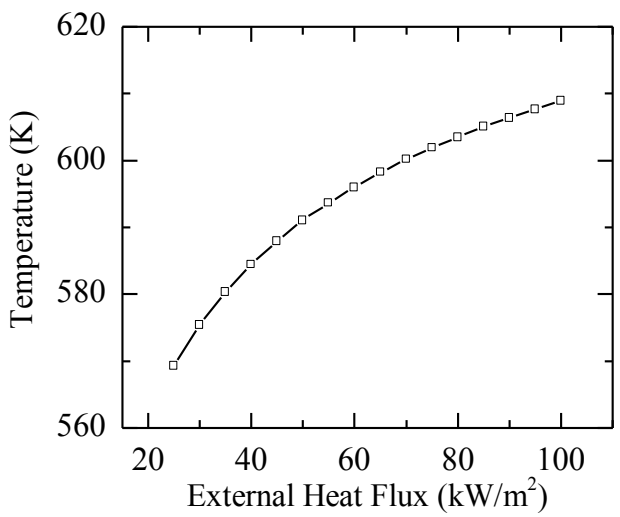

(b)

Fig. 3. (a) Modeled temperature at maximum reaction rate at different external heat fluxes; (b) Change of modeled temperature at maximum reaction rate with external heat flux.

\section{Combustion characteristics of corrugated cardboard flames}

Figure 4a shows the mass yield and net heat of combustion of volatiles determined using Eq. 5 following the methodology described above. Note that volatile yields exceed the value listed in Table 1 (determined through ASTM D3172 [28]) at heat flux levels higher than $50 \mathrm{~kW} / \mathrm{m}^{2}$. The results indicate that a more severe heat treatment than that used in the ASTM D3172 test is responsible for the higher volatile yield observed. The differences in volatiles heat of combustion and in mass loss for various heat fluxes are relatively small, however, within $\pm 6-8 \%$ of the average values. In the case of cellulosic materials such as corrugated cardboard, the major elements in the virgin material are carbon, hydrogen, and oxygen, see Table 1. Figure $4 \mathrm{~b}$ shows the variation of atomic hydrogen/carbon and oxygen/carbon ratios of virgin material and the chars formed after pyrolysis at different external heating conditions. All char data show significantly lower $\mathrm{H} / \mathrm{C}$ and $\mathrm{O} / \mathrm{C}$ ratios than those of virgin material, and declining trends of both ratios 
with increased heat fluxes. Therefore, the charring process demonstrates higher removal rates of hydrogen and oxygen than carbon, and forms char with a higher specific chemical enthalpy than that of both volatiles and virgin material. Such behavior can also be interpreted from the average net heat of combustion of the volatiles shown in Fig. 4a. All four heat of combustion values of volatiles are lower than that of virgin material. An increase of volatiles' heat of combustion from 12.3 to $14.0 \mathrm{~kJ} / \mathrm{g}$ is attributed to the $10 \mathrm{wt} \%$ of mass that is converted from char to volatiles. This is in line with expectations of higher reaction temperature and heavier volatile composition with higher level of heat flux, which was discussed in the previous section.

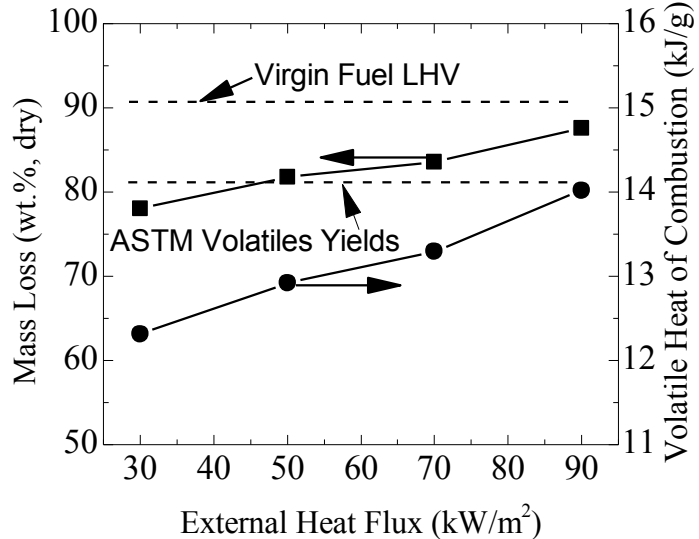

(a)

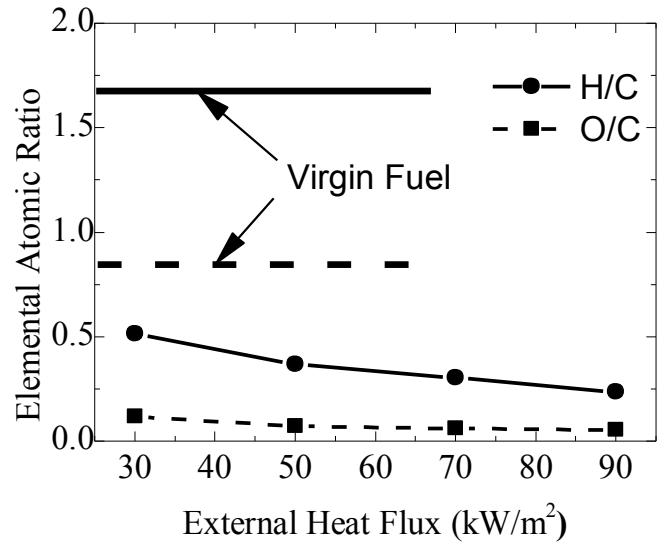

(b)

Fig. 4. (a) Mass fraction and heat of combustion of volatiles at different external heat fluxes; (b)

Comparison of elemental compositions of virgin fuel and chars formed at different external heat fluxes.

The faster release rate of fuel mass than specific chemical enthalpy was also evident in the combustion tests performed in this study. Figure 5a shows the heat of combustion of volatiles released during a combustion test as a function of fractional mass loss; its probability distribution function (PDF) with respect to the fuel mass is shown in Fig. 5b. The data shown in Fig. 5 were obtained for a heat flux level of $50 \mathrm{~kW} / \mathrm{m}^{2}$ and an initial sample weight of $75.8 \mathrm{~g}$. Data for other external heat fluxes are similar to those reported in Fig. 5. The transient heat of combustion of volatiles is calculated as:

$\Delta h_{c, v o l}=\frac{\dot{Q}_{c h}}{\dot{m} \chi_{c h}}$

Where $\Delta h_{c, v o l}$ is the volatile heat of combustion and is given a lowercase notation to differentiate its measurement in the FPA from quantities determined via bomb calorimetry testing and through Eqs. 1-5, $\mathcal{Q}_{c h}$ is the chemical heat release rate (measured via $\mathrm{CO}$ and $\mathrm{CO}_{2}$ generation calorimetry), $\dot{m}$ is the mass loss rate, and $\chi_{\mathrm{ch}}$ is the average chemical combustion efficiency, which is calculated based on the integrated chemical heat release rate and theoretical heat of combustion from the following:

$\chi_{c h}=\frac{\int \dot{Q}_{c h} d t}{\Delta H_{c, v i r g i n}^{0} \int \dot{m} d t}$

Equation 6 assumes that all volatiles generated have the same combustion efficiency as the averaged combustion efficiency of the whole combustion process (Eq. 7). The PDF of the fuel mass with heat of combustion has a mean value of $14.3 \mathrm{~kJ} / \mathrm{g}$, and a standard deviation of $2.5 \mathrm{~kJ} / \mathrm{g}$. The mean heat of combustion is higher than that reported in Fig. 4a, which indicates the presence of char oxidation. The heat of combustion of volatiles increases with pyrolysis and combustion progress due to both variations of volatile composition and increased char oxidation. Despite the noted char involvement in the combustion process at the given test conditions, the initial heat of combustion for mass loss fractions less than 0.25 is lower than the average value of $12.9 \mathrm{~kJ} / \mathrm{g}$ for $50 \mathrm{~kW} / \mathrm{m}^{2}$ reported in Fig. 4a. Thus, the volatiles released in 
the early stage of pyrolysis should be comprised of chemical compounds with high degrees of oxygenation, which is associated with a lower specific chemical enthalpy. Such a variation of volatiles with fuel fractional mass loss is consistent with the results obtained from alpha-cellulose material [16].

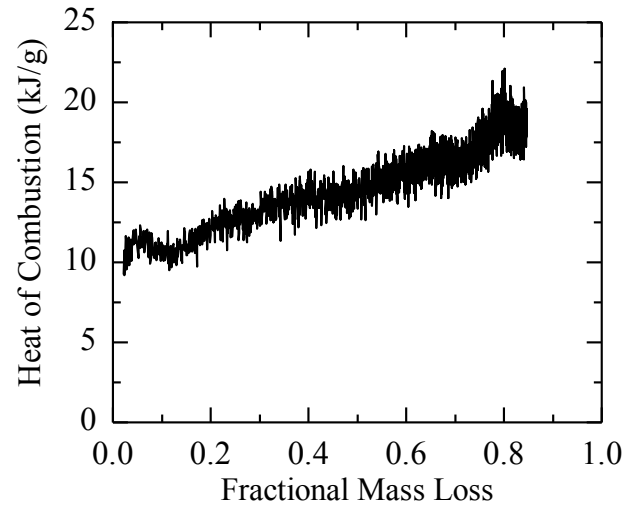

(a)

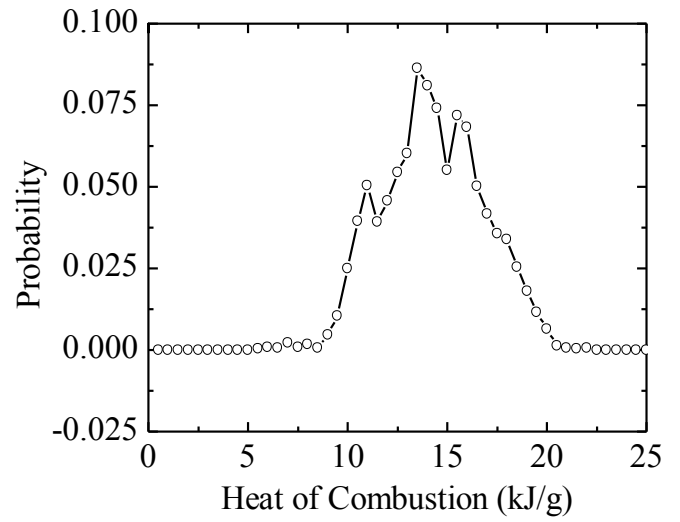

(b)

Fig. 5. (a) Heat of combustion of corrugated cardboard volatiles determined during FPA testing; (b) Massaveraged PDF of the data shown in (a).

\section{Radiation characteristics of corrugated cardboard flames}

As discussed in the previous section, the chemical composition of volatiles varies with the extent of charring as well as the pyrolysis process itself. This prevents a precise quantification of an instantaneous chemical heat release rate and, in turn, an instantaneous radiant fraction. Nevertheless a time-dependent radiant fraction $\chi_{r}(t)$ is reported here based on the following equation:

$\chi_{r}(t)=\frac{\dot{Q}_{r}}{\dot{Q}_{c h} / \chi_{c h}}$

As discussed previously, the heat of combustion of volatiles changes significantly during the combustion process, the definition of $\chi_{r}(t)$ given by Eq. 8 better approximates the specific chemical enthalpy released during combustion rather than using the multiplication of fuel mass loss and heat of combustion in the denominator. The radiative heat release rate, $\dot{Q}_{r}$, was determined by single point heat flux measurements interpreted using a weighted multi-point source model [29]:

$\dot{Q}_{r}=4 \pi \dot{q}_{m}^{\prime \prime}\left(\sum_{j=1}^{N} w_{j} \tau_{j} \frac{\cos \phi_{j}}{S_{j}}\right)^{-1}$

Where $\dot{q}_{m}^{\prime \prime}$ is the measured heat flux, $N$ is the number of point sources considered and presently set to $40, S_{j}$ and $\phi_{j}$ are geometry related variables defined in the same fashion as that reported elsewhere [29], $\tau_{j}$ is the transmissivity over the distance $S_{j}$ (assumed to be unity for near-field measurements), and $w_{j}$ is the weight of each point source so that $\Sigma w_{j}=1$. The instantaneous flame height was measured from visual camera records and used to derive the geometrical parameters of Eq. 9. The distribution of $w_{j}$ along the flame height was assumed to be triangular with a peak located at $25 \%$ of the flame height [30]. Varying the peak position from $25 \%$ to $50 \%$ of the flame height causes less than $1 \%$ change in the results of Eq. 9 .

Figure 6 compares radiant fractions measured from corrugated cardboard flames at external heat fluxes of 30 and $90 \mathrm{~kW} / \mathrm{m}^{2}$ as functions of fractional mass loss. For both external heat flux conditions, the radiant fractions demonstrate an increasing trend with mass loss specifically sharp increase for mass loss fraction exceeding 0.7 . This is consistent with the sharp increase characteristic reaction temperature with mass loss illustrated by Fig. 3a and corresponding changes in volatile composition. This observation indicates that the 
variation in the composition of volatiles not only affects the release rate of specific chemical enthalpy, but also changes the sooting propensity of the volatiles. Compared to radiant fractions at an external heat flux of $90 \mathrm{~kW} / \mathrm{m}^{2}$, the radiant fractions measured for $30 \mathrm{~kW} / \mathrm{m}^{2}$ are shown for mass loss fractions from 0.15 to 0.8 (the volatiles released prior to a fractional mass loss of 0.15 have too low a heat of combustion to be ignited, and the mass loss rate after a fractional mass loss of 0.8 is too low to sustain a flame). Within this range, radiant fractions measured with an external heat flux of $90 \mathrm{~kW} / \mathrm{m}^{2}$ are higher than those at a lower heat flux of $30 \mathrm{~kW} / \mathrm{m}^{2}$. Once again this can be explained by the changes in the thermal regime of pyrolysis reactions with heat flux illustrated by Fig. 3 and corresponding changes of volatiles composition.

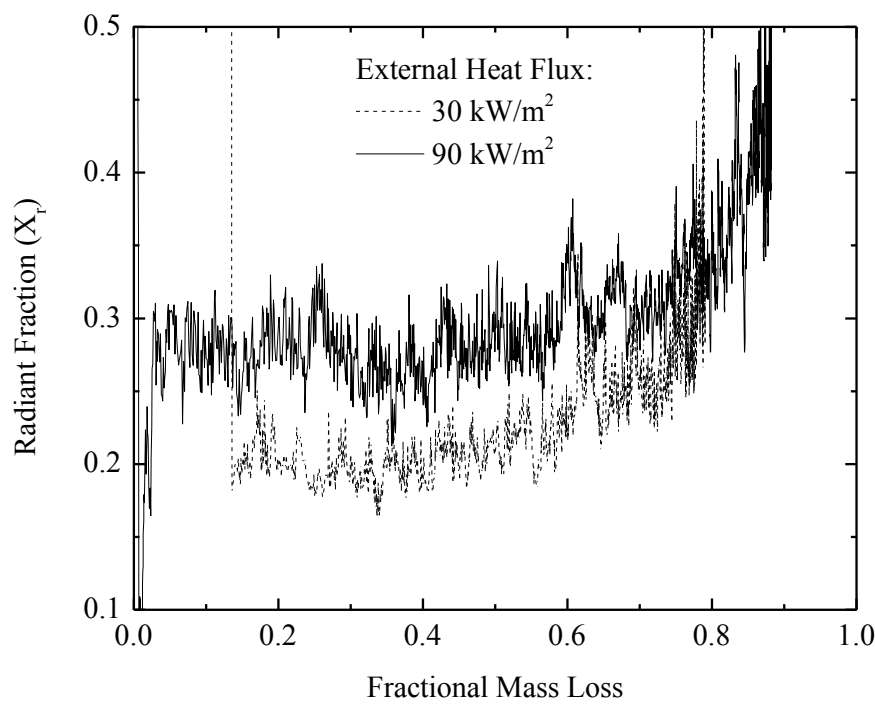

Fig. 6. Radiant fractions of corrugated cardboard flames at different external heat fluxes.

Figure 7a compares radiant fractions measured at four external heat fluxes of $30,50,70$, and $90 \mathrm{~kW} / \mathrm{m}^{2}$. The data presented are averaged values between fractional mass losses of 0.2 and 0.6. Selection of this range allows a consistent comparison of radiant fraction data for all heat fluxes considered. However, these averaged values do not reflect the increasing trend for mass loss fractions higher than 0.6 . Figure 7 a shows the combustion efficiency is unchanged, within experimental uncertainty, for the range of external heat fluxes from 30 to $70 \mathrm{~kW} / \mathrm{m}^{2}$, then decreases as the heat flux increases to $90 \mathrm{~kW} / \mathrm{m}^{2}$. At $90 \mathrm{~kW} / \mathrm{m}^{2}$, the combustion efficiency decreases because of increased combustion incompleteness in the form of smoke yields. On the other hand, radiant fraction increases with elevated external heat fluxes, from $20 \%$ at $30 \mathrm{~kW} / \mathrm{m}^{2}$ to $28 \%$ at $90 \mathrm{~kW} / \mathrm{m}^{2}$. This change in radiant fraction with external heat flux is consistent with observed smoke generation efficiency shown in Fig. 7b. The smoke generation efficiency is defined as:

$f_{s}=\frac{1}{\varepsilon_{C, \text { volatiles }}} \frac{\int \dot{G}_{s} d t}{\int \dot{m} d t}$

Where $\dot{G}_{s}$ is the smoke mass generation rate and $\varepsilon_{\mathrm{C}, \text { volatiles }}$ is the carbon mass fraction in the volatiles. Both the increased radiant fraction and smoke efficiency with elevated external heat flux indicate that the increased fuel heating rate and characteristic pyrolysis temperature at higher external heat flux affects the chemical composition of volatiles released during pyrolysis, resulting in an increased sooting propensity, consistent with [23, 31]. 


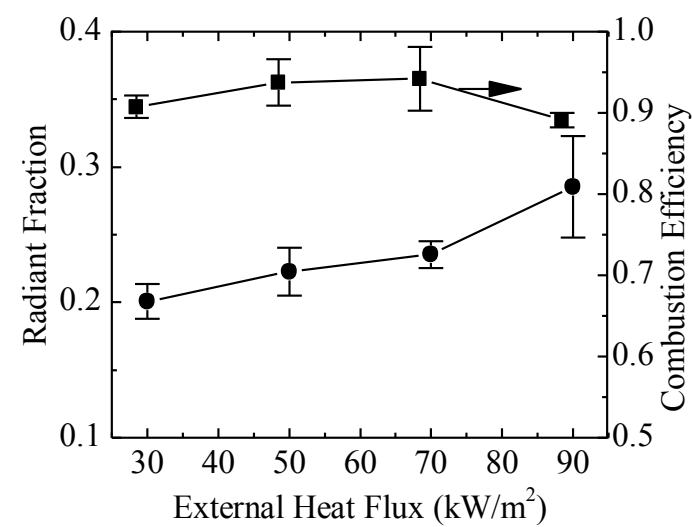

(a)

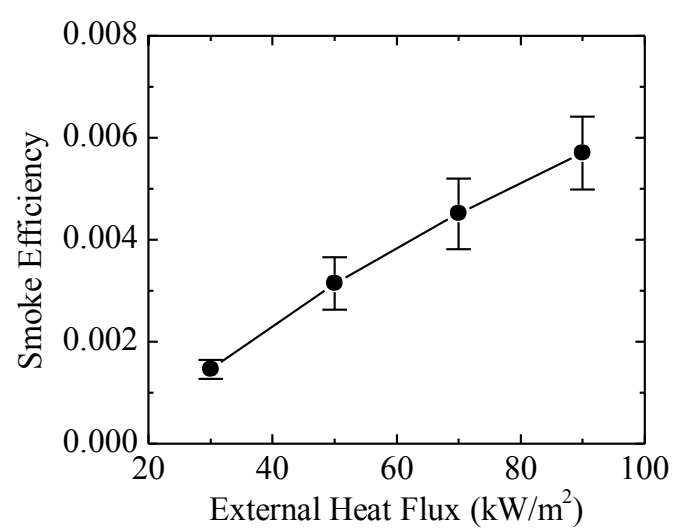

(b)

Fig. 7. Effect of external heat flux on (a) radiant fractions and (b) smoke generation efficiency of corrugated cardboard flames.

\section{Smoke points of corrugated cardboard}

Figure 8 shows smoke-point heights of laminar diffusion flames of combusting volatiles generated by pyrolyzing corrugated cardboard at nominal external heat fluxes of 40 and $90 \mathrm{~kW} / \mathrm{m}^{2}$. At an external heat flux of $40 \mathrm{~kW} / \mathrm{m}^{2}$, smoke point is not measurable before a mass loss fraction of 0.18 because the volatiles are not ignitable due to high inert content (e.g. $\mathrm{CO}_{2}, \mathrm{H}_{2} \mathrm{O}$ ). At both heat flux levels, smoke point could not be measured at the latter stages because pyrolysis reactions were nearly completed and the volatile flow rate was too low to sustain a laminar flame. For example, the smoke point at $90 \mathrm{~kW} / \mathrm{m}^{2}$ could be measured up to a fractional mass loss of 0.84 due to a higher mass loss rate at this condition as opposed to the $40 \mathrm{~kW} / \mathrm{m}^{2}$ case.

Previous studies measuring smoke points of solid fuels relied on a specific experiment to extract volatiles $[18,19]$. The smoke points were measured for volatiles released at the specific heating conditions and were unique to the experimental design. The decreasing smoke point height trend with increased fractional mass loss shown in Fig. 8 indicates that the sooting propensity of the volatiles is increased as pyrolysis proceeds. Such a trend is consistent with data shown in Fig. 6 in which radiant fractions of turbulent buoyant diffusion flames of corrugated cardboard increase with fuel fractional mass loss. Figure 8 shows that the smoke point heights measured at an external heat flux of $90 \mathrm{~kW} / \mathrm{m}^{2}$ are lower than those measured at $40 \mathrm{~kW} / \mathrm{m}^{2}$. This, again, indicates that the chemical composition of volatiles are dependent on both the mass loss level and sample heating history, which is also consistent with radiant fraction data shown in Fig. 7a and with the illustration of the thermal regime of pyrolysis reaction in Fig. 3. From a global perspective, the increased specific chemical enthalpy and sooting propensity of volatiles with mass loss fraction are also consistent. The volatiles released at the early stage of pyrolysis contain a relatively high $\mathrm{O} / \mathrm{C}$ ratio, which has a lower specific chemical enthalpy. At the latter stage, the $\mathrm{O} / \mathrm{C}$ ratio of volatiles decreases and the sooting propensity increases because of oxygen depletion in the volatiles. Since corrugated cardboard is a cellulosic material of aliphatic nature [32], the volatiles formed from its pyrolysis are also mainly aliphatic. Therefore, the variation in observed sooting propensity and radiation fraction are attributed to changes in the oxygen content of the volatiles [5] rather than aromaticity. 


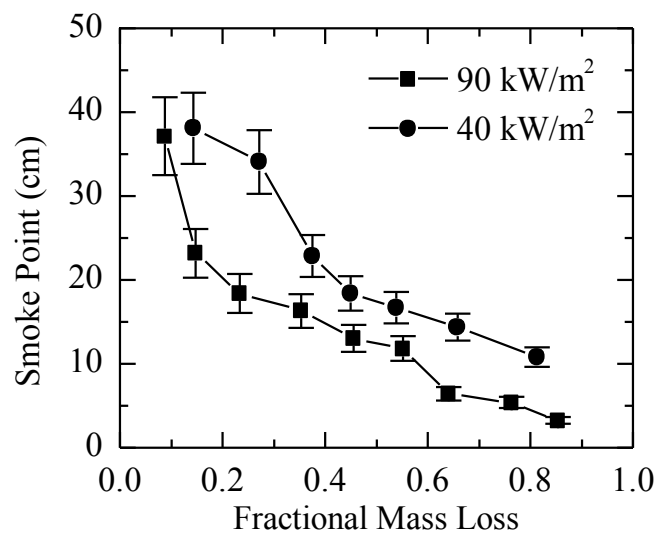

Fig. 8. Smoke point height of corrugated cardboard at different external heat fluxes.

In summary, the radiation properties and combustion behavior of practical solid fuels such as corrugated cardboard are significantly richer than those of individual gases, liquids, and some solid fuels. It is hardly possible to define a universal correlation between radiant fraction, incompleteness of combustion, laminar smoke point, and soot yield for such complex fuels. The notion that the radiation and combustion properties mentioned above are correlated is not challenged by the results of this study. Indeed, there is consistent behavior between radiation emission, heat of combustion of volatiles, and their sooting propensity. The challenge is that the properties of volatiles change with the thermal regime associated with the pyrolysis reaction progress. This complicates applications of simple radiation fraction correlations in various analytical and numerical models of flame spread over solid fuels and fire growth.

To overcome this complication one may either be satisfied with a simplified approach or develop an advanced model. In the simplified approach the mass average combustion properties, such as heat of combustion, and mass averaged radiant fraction can be defined for a single pyrolysate. This is feasible in situations when variation of heat of combustion and radiant fraction of volatiles generated within representative heating rates (about $10-15 \%$ for corrugated cardboard) are acceptable and changes with reaction progress are not essential. In addition, the average radiation fraction of the fuel of interest should be measured for representative range of conditions. Presently, it would not be possible to directly infer radiant fraction from smoke yield / smoke point data. An advanced approach would require multiple fuels (at least 2) as volatiles with their representative combustion and radiation properties. These fuels should be generated in multiple pyrolysis reactions. Parameters of such an advanced pyrolysis model should be determined not only to describe thermal decomposition in terms of mass loss rates and solid temperatures but should also be cross-correlated with combustion and radiation properties of volatile mixtures.

\section{CONCLUSIONS}

Combustion and radiation characteristics were investigated for flames generated from corrugated cardboard subjected to different external radiant heat fluxes in a Fire Propagation Apparatus. A higher external radiant heat flux incurs a faster fuel heating rate, and shifts pyrolysis reactions to a higher temperature range. The volatiles released from the pyrolysis process of corrugated cardboard have an increasing specific chemical enthalpy as pyrolysis progresses; this can be attributed to faster release rates of fuel hydrogen and oxygen as opposed to carbon. Radiant fractions of buoyant turbulent diffusion flames of volatiles released from corrugated cardboard increase with reaction progress specifically at high mass loss fractions for a given heating condition. Radiant fractions, averaged between 20-60\% mass conversion levels, increase from 0.20 to 0.28 when the external heat flux increases from 30 to $90 \mathrm{~kW} / \mathrm{m}^{2}$. This is explained with the shift of pyrolysis reactions to a higher temperature range. Consistent with radiant fraction, smoke point height measured on laminar diffusion flames of pyrolysate from corrugated cardboard reduces from 38 to less than $1 \mathrm{~cm}$ with increased fractional mass loss. Smoke point heights measured at a higher external heat flux are lower than those for a lower heat flux. The complex chemical composition of corrugated cardboard combined with the thermal regime of pyrolysis reactions has been shown to considerably affect its combustion and radiation characteristics through variations of volatiles properties including both specific chemical enthalpy and sooting propensity. Such variations of the volatile composition and their combustion 
and radiation properties impose limitations on the accuracy of models for radiation from solid fuel flames based on constant radiant fractions of volatiles as their radiation property. Advanced radiation models for complex fuels should consider the dynamic radiant fraction features of buoyant diffusion flames shown herein for corrugated cardboard.

\section{ACKNOWLEDGEMENTS}

This study was funded by FM Global and performed within the framework of the FM Global Strategic Research Program on Fire Modeling. The authors gratefully acknowledge S.D. Ogden for carrying out FPA testing.

\section{REFERENCES}

[1] Tewarson, A., "Smoke Point Height and Fire Properties of Materials," National Institute of Standards and Technology Report NIST-GCR-88-555, 1988.

[2] de Ris, J.L., Wu, P.K., and Heskestad, G., (2000) Radiation Fire Modeling, Proceedings of the Combustion Institute 28: 2751-2759, http://dx.doi.org/10.1016/S0082-0784(00)80696-7.

[3] Markstein, G.H., (1985), Relationship between Smoke Point and Radiant Emission from Buoyant Turbulent and Laminar Diffusion Flames, Proceedings of the Combustion Institute 20: 1055-1061, http://dx.doi.org/10.1016/S0082-0784(85)80595-6.

[4] Orloff, L., de Ris, J., and Delichatsios, M.A., (1992) Radiation from Buoyant Turbulent Diffusion Flames, Combustion Science and Technology 84: 177-186, http://dx.doi.org/10.1080/00102209208951852.

[5] Tewarson, A., (2004) Combustion Efficiency and its Radiative Component, Fire Safety Journal 39: 131-141, http://dx.doi.org/10.1016/j.firesaf.2003.07.004.

[6] Tewarson, A., "Generation of Heat and Chemical Compounds in Fires." Chapter 3-4 in P.J. DiNenno, D. Drysdale, C.L. Beyler, W.D. Walton, R.L.P. Custer, J.R. Hall, Jr., J.M. Watts, Jr. (Eds.), SFPE Handbook of Fire Protection Engineering, 3rd ed., National Fire Protection Association, Quincy, 2002.

[7] Lautenberger, C.W., de Ris, J.L., Dembsey, N.A., Barnett, J.R., and Baum, H.R., (2005) A Simplified Model for Soot Formation and Oxidation in CFD Simulation of Non-Premixed Hydrocarbon Flames, Fire Safety Journal 40: 141-176, http://dx.doi.org/10.1016/j.firesaf.2004.10.002.

[8] Beji, T., Zhang, J.P., and Delichatsios, M.A., (2008) Determination of Soot Formation Rate from Laminar Smoke Point Measurements, Combustion Science and Technology 180: 927-940, http://dx.doi.org/10.1080/00102200801894398.

[9] Chatterjee, P., de Ris, J.L., Wang, Y., and Dorofeev, S.B., (2011) A Model for Soot Radiation in Buoyant Diffusion Flames, Proceedings of the Combustion Institute 33: 2665-2671, http://dx.doi.org/10.1016/j.proci.2010.06.112.

[10] Wang, Y., Chatterjee, P., and de Ris, J.L., (2011) Large Eddy Simulation of Fire Plumes, Proceedings of the Combustion Institute 33: 2473-2480, http://dx.doi.org/10.1016/j.proci.2010.07.031 (also see fmglobal.com/modeling).

[11] de Ris, J.L. and Orloff, L., (2005) Flame Heat Transfer Between Parallel Panels, Fire Safety Science 8: 999-1010, http://dx.doi.org/10.3801/IAFSS.FSS.8-999.

[12] Krishnamoorthy, N., Chaos, M., Khan, M.M., Chatterjee, P., Wang, Y., and Dorofeev, S.B., "Experimental and Numerical Study of Flame Spread in Parallel Panel Geometry," Proceedings of the $6^{\text {th }}$ International Seminar on Fire and Explosion Hazards (ISFEH6), 2010, pp.230-240, http://dx.doi.org/10.3850/978-981-08-7724-8 03-07. 
[13] Santo, G. and Tamanini, F., (1981) Influence of Oxygen Depletion on the Radiative Properties of PMMA Flames, Proceedings of the Combustion Institute 18: 619-631, http://dx.doi.org/10.1016/S0082-0784(81)80067-7.

[14] Jiang, F., (1998) Flame Radiation from Polymer Fires, Fire Safety Journal 30: 383-395, http://dx.doi.org/10.1016/S0379-7112(97)00016-7.

[15] Browne, F.L. and Brenden, J.J., "Heats of Combustion of the Volatile Pyrolysis Products of Ponderosa Pine,” US Forest Service Research Paper FPL 19, Madison, WI, 1964.

[16] Parker, W.J. and LeVan, S.L., (1989) Kinetic Properties Of The Components Of Douglas-fir And The Heat Of Combustion Of Their Volatile Pyrolysis Products, Wood and Fiber Science 21: 289305.

[17] Olson, D.B., Pickens, J.C., and Gill, R.J., (1985) The Effects of Molecular Structure on Soot Formation II. Diffusion Flames, Combustion and Flame 62: 43-60, http://dx.doi.org/10.1016/0010-2180(85)90092-6.

[18] Delichatsios, M.A., (1993) Smoke Yields from Turbulent Buoyant Jet Flames, Fire Safety Journal 20: 299-311, http://dx.doi.org/10.1016/0379-7112(93)90052-R.

[19] de Ris, J.L. and Cheng, X.F., (1994) The Role of Smoke-Point in Material Flammability Testing, Fire Safety Science 4: 301-312, http://dx.doi.org/10.3801/IAFSS.FSS.4-301.

[20] Chaos, M., Khan, M.M., and Dorofeev, S.B., (2013) Pyrolysis of Corrugated Cardboard in Inert and Oxidative Environments, Proceedings of the Combustion Institute 34: 2583-2590, http://dx.doi.org/10.1016/j.proci.2012.06.031.

[21] ASTM E 2058-13, Standard Test Methods for Measurement of Synthetic Polymer Material Flammability Using a Fire Propagation Apparatus (FPA). ASTM International, West Conshohocken, PA, 2013, DOI: 10.1520/E2058-13, www.astm.org.

[22] ISO 12136:2011, Reaction to Fire tests - Measurement of Material Properties Using a Fire Propagation Apparatus. International Organization for Standardization, Geneva, Switzerland.

[23] Zeng, D., Chaos, M., Khan, M.M., and Dorofeev, S.B. "An Experimental Study of Smoke Generated from Solid Fuel," Proceedings of the Fire and Materials 2013 Conference, January 2830, 2013, San Francisco, CA, pp. 79-89.

[24] Lee, C.K., Chaiken, R.F., and Singer, J.M., (1977) Charring pyrolysis of wood in fires by laser simulation, Symposium (International) on Combustion, 16:1459-1470, http://dx.doi.org/10.1016/S0082-0784(77)80428-1.

[25] McKinnon, M.B., (2012) Development of a Model for Flaming Combustion of Double-Wall Corrugated Cardboard, M.S. thesis, University of Maryland, pp. 73.

[26] Chaos, M., Khan, M.M., Krishnamoorthy, N., de Ris, J.L., and Dorofeev, S.B., (2011) Evaluation of Optimization Schemes and Determination of Solid Fuel Properties for CFD Fire Models Using Bench-Scale Pyrolysis Tests, Proceedings of the Combustion Institute 33: 2599-2606, http://dx.doi.org/10.1016/j.proci.2010.07.018.

[27] Chaos, M., Wang, Y., and Dorofeev, S.B. "CFD Modeling of Flame Spread over Corrugated Cardboard Panels”, International Congress on Fire Computer Modeling, October 18-19, 2012, Universidad de Cantabria, Santander, Spain.

[28] ASTM D3172-07a, Standard Practice for Proximate Analysis of Coal and Coke, ASTM International, West Conshohocken, PA, 2007, DOI:10.1520/D3172-07a (www.astm.org).

[29] Hankinson, G. and Lowesmith, B.J., (2012) A Consideration of Methods of Determining the Radiative Characteristics of Jet Fires, Combustion and Flame 159: 1165-1177, http://dx.doi.org/10.1016/j.combustflame.2011.09.004. 
[30] Hamins, A., Klassen, M., Gore, J., and Kashiwagi, T., (1991) Estimate of Flame Radiance Via a Single Location Measurement in Liquid Pool Fires, Combustion and Flame 86: 223-228, http://dx.doi.org/10.1016/0010-2180(91)90102-H.

[31] Williams, P.T. and Besler, S., (1996) The Influence of Temperature and Heating Rate on the Slow Pyrolysis of Biomass, Renewable Energy 7: 233-250, http://dx.doi.org/10.1016/09601481(96)00006-7.

[32] Klemm, D., Heublein, B., Fink, H.-P., and Bohn, A., (2005) Cellulose: Fascinating Biopolymer and Sustainable Raw Material, Angewandte Chemie International Edition 44: 3358-3393, http://dx.doi.org/10.1002/anie.200460587. 